\title{
Right Ventricular Myocardial Infarction as an Independent Predictor of Prognosis in Acute Inferior Myocardial Infarction
}

\author{
Nazmul Huda ${ }^{1}$, Zahidus Sayeed $^{2}$, A R M S Ekram ${ }^{3}$, Khan MMR $^{4}$, MK Rahman $^{4}$
}

\begin{abstract}
Background: Acute inferior myocardial Infarction frequently involves the right ventricle and associated with significant morbidity and mortality. We hypothesized that right ventricular involvement may affect the prognosis of patients with inferior myocardial infarctions.

Methodology: In 100 consecutive patients admitted to the hospital with acute inferior myocardial infarction, we assessed the incidence and prognostic factors for in-hospital outcome. RVMI (Right ventricular myocardial infarction) was diagnosed by $\geq 1 \mathrm{~mm}$ ST elevation in lead $V_{4 R}$ in right sided electrocardiogram.

Result: RVMI was found in $31(31 \%)$ of patients of acute inferior myocardial infarctions. Major complications as hypotension and cardiogenic shock occurred in $96.7 \%$ and $64.5 \%$ patients respectively and in-hospital mortality was $\mathbf{4 1 . 9 \%}$. Whereas major complications as hypotension and cardiogenic shock occurred in $10.1 \%$ and $2.8 \%$ patients respectively and in hospital mortality was $\mathbf{2 . 8 \%}$ of patients without right ventricular infarction among the inferior myocardial infarction. Multiple logistic regression analysis showed right ventricular infarction to be independent of and superior to all other clinical variables available on admission for the prediction of in hospital mortality (relative risk 88.37 percent, $95 \%$ confidence interval 7.33 to 1064.80; $p=0.000$ ) and major complications as hypotension (relative risk $394.22,95 \%$ confidence interval 32.04 to $4849.07 ; p=0.000$ ) and cardiogenic shock (relative risk $272.36,95 \%$ confidence interval, 16.38 to $4526.35 ; p=0.000$ ).
\end{abstract}

Conclusion: RVMI commonly occurs in inferior myocardial infarction. It is a strong and independent predictor of major complications and in-hospital mortality. Early detection and appropriate monitoring can reduce its high mortality rate.

Keywords: Acute inferior myocardial infarction, RVMI, Prognostic outcome.

TAJ 2013; 26: 08-13

\section{Introduction}

The description of right ventricular infarction appeared more than 70 years ago, ${ }^{1}$ yet for decades it was not considered an important clinical entity. In 1974, Cohn and coworkers ${ }^{2}$ published their classic report on right ventricular infarction as a distinct clinical entity.
Clinical studies demonstrated that right ventricular involvement occurs almost exclusively in patients with inferior wall infarction and postmortem studies revealed that it was 19 to 51 percent of patients with acute inferior myocardial infarctions. ${ }^{3}$

${ }^{1}$ Assistant Professor, Department of Medicine, Rajshahi Medical College, Rajshahi.

${ }^{2}$ Assistant Professor, Department of Cardiology, Rajshahi Medical College, Rajshahi.

3 Professor, Department of Medicine, Rajshahi Medical College, Rajshahi.

${ }^{4}$ Associate Professor, Department of Medicine, Rajshahi Medical College, Rajshahi. 
Clinically, RVMI may be missed; for the classical triad of hypotension, clear lung fields and elevated jugular venous pressure does not always occur. ${ }^{4}$ Although quite specific, this triad has a sensitivity of less than 25 percent, but distended neck veins alone have been shown to be 88 percent sensitive and 69 percent specific. ${ }^{4}$ Kussmaul's sign is highly sensitive and specific for right ventricular infarction. ${ }^{5}$

The diagnosis of right ventricular infarction can be made from the physical examination, echocardiography, first-pass, or equilibrium radionuclide, ventriculography, technetiumpyrophosphate myocardial scanning, and hemodynamic measurements. But right precordial electrocardiography, ${ }^{6}$ at the time of presentation is the most readily available, simplest, inexpensive and currently gold standard of these techniques. ST-segment elevation $\geq 1 \mathrm{~mm}$ in right chest lead $\mathrm{V}_{4 \mathrm{R}}$ is $70 \%$ sensitive and nearly $100 \%$ specific for RVMI. $^{7}$

We looked at the frequency and in-hospital prognostic factors of outcomes of RVMI complicating IMI in the setting of a tertiary medical college hospital.

\section{Methodology}

This descriptive observational study was carried out on 100 consecutive patients of acute inferior myocardial infarction admitted in coronary care unit of Rajshahi medical college hospital. Patients were treated according to AHA guidelines. Informed consent was obtained from all patients and ethical review was done by institutional review board. Right sided ECG was routinely done in all patients presenting with acute IMI within 10 hrs of symptoms of onset at the time of admission. RVMI was diagnosed based on $\geq 1-\mathrm{mm}$ STsegment elevation in $\mathrm{V}_{4 \mathrm{R}}$ lead. ${ }^{7}$

Patients with RVMI constituted group A ( $n=31)$ and patients without RVI constituted group $\mathrm{B}$ $(n=69)$ and served as controls.

Prognostic assessment was studied for all patients during in hospital course. Prognostic effect of RVI was evaluated in relation to other clinical variables available at the time of admission including age, sex, smoking, hypertension, diabetes mellitus, hypercholesteromia and thombolytic therapy.

Data were analyzed by SPSS V-15 software. Significant test were done by Chi-square test. The independent prognostic effect of selected clinical variables of in-hospital mortality as well as short term complications were assessed with multiple logistic regression analysis. All tests of significance were two tailed and a $\mathrm{p}$ value of $\leq 0.05$ was considered to indicate statistical significance.

\section{Results}

Right ventricular infarction occurred among thirty one patients (31\%) presenting with acute inferior myocardial infarction. Table 1 shows the patient characteristics of both groups. Mean $( \pm S D)$ age of group A was $55.26 \pm 10.61$ yrs and group B was $51.25 \pm 9.95$ and it revealed no significant difference $(p=0.08)$. Male and female ratio in group A was 5.2:1and in group B was 6.6:1.

Total thirty seven (37\%) patients were found to be hypotensive in which thirty (96.7\%) patients belong to group A and only seven (10.1\%) in group $\mathrm{B}(\mathrm{p}=.00)$.

High degree AV block (second degree and complete heart block) were more in group B (11.6\% vs $6.4 \%)$. Three patients $(4.3 \%)$ of group $\mathrm{B}$ had required temporary pacing for complete heart block.

Twenty patients (64.5\%) of group A had developed cardiogenic shock and it became irreversible in thirteen (65\%) of them and ultimately death ensued. Incidence of cardiogenic shock was highly significant in group A (group A: $64.5 \%$ vs group B $2.8 \%$; $\mathrm{p}=0.00$ ).

Independent prognostic value of RVI with other clinical criteria for the incidence of death (Table 2):

Table 2 showed the logistic regression analysis of independent prognostic value of RVI with other clinical variables available at the time of hospitalization. The logistic regression relative risks for the age groups 28-40, 41- 50, 51-60 and $>60 y$ rs. were shown in table 2 . Considering the first age group 28-40 as reference category, the relative risk of patients of other age groups did not 
show any statistically significant association. Similarly, male patients, smoker, hypertensive, diabetic, patients of hypercholesteromia and patients who did not receive thombolytic therapy did not show statistically significant prognostic influence for the incidence of death.

But patients with right ventricular infarction were 88.37 times higher risk (95\% confidence interval, 7.334- 1064.8) of poor prognosis than patients without right ventricular infarction which was statistically highly significant $(\mathrm{p}=0.000)$.

Independent prognostic value of RVI with other clinical criteria for the incidence of major complications (Table 3):

Table 3 showed the logistic regression analysis of independent prognostic value of RVI with other clinical variables available at the time of hospitalization for the incidence of major complications (Hypotension, high degree AV block and cardiogenic shock).

\section{Hypotension}

Age, male patients, smoker, hypertensive, diabetic, patients of hypercholesteromia and patients who did not receive thombolytic therapy did not show statistically significant influence for the incidence of hypotension. But patients with right ventricular infarction were 394.2 times higher risk (95\% confidence interval, 32.04- 4849.07) of developing hypotension than patients without right ventricular infarction which was statistically highly significant $(\mathrm{p}=0.000)$.

\section{High degree AV block:}

Considering the first age group 28-40 as reference category, the relative risk of patients aged 41-50 yrs, 51-60 yrs and >60 yrs were 1.2E+008, 0.907 and $4.7 \mathrm{E}+008$ respectively which were statistically insignificant $\quad(p=0.99 ; \quad p=0.99 ; \quad p=0.99$ respectively). Male patients, smoker, hypertensive, diabetic, patients of hypercholesteromia and patients who did not receive thombolytic therapy did not show statistically significant influence for the incidence of high degree AV block. But surprisingly, patients with right ventricular infarction were 0.049 times higher risk (95\% confidence interval, 0.058- 2.879) of developing high degree AV block than patients without right ventricular infarction which was also statistically insignificant $(\mathrm{p}=0.36)$.

\section{Cardiogenic shock:}

Age, male patients, smoker, hypertensive, diabetic, patients of hypercholesteromia and patients who did not receive thombolytic therapy did not show any statistically significant influence for the incidence of cardiogenic shock. But patients with right ventricular infarction were 272.3 times higher risk (95\% confidence interval, 16.384526.35) of developing cardiogenic shock than patients without right ventricular infarction which was statistically highly significant $(\mathrm{p}=0.000)$.

Table 1: Patients characteristics, major complications and mortality during hospitalization.

\begin{tabular}{|c|c|c|c|}
\hline $\begin{array}{c}\text { Age } \\
\text { (years) }\end{array}$ & $\begin{array}{c}\text { IMI + RVI } \\
\text { (Group-A) } \\
(\mathrm{n}=31)\end{array}$ & $\begin{array}{c}\text { IMI } \\
\text { (Group-B) } \\
(\mathrm{n}=69)\end{array}$ & p value \\
\hline Total patients, $\mathrm{N}$ & 31 & 69 & - \\
\hline Male:female & $5.2: 1$ & $6.6: 1$ & 0.08 \\
\hline Age (mean \pm SD) yrs & $55.26 \pm 10.61$ & $51.25 \pm 9.95$ & 0.04 \\
\hline Smoking, $\mathrm{n}(\%)$ & $26(83.8)$ & $45(65.2)$ & 0.02 \\
\hline Hypertension, $\mathrm{n}(\%)$ & $15(48.3)$ & $17(24.6)$ & 0.07 \\
\hline Diabetes, $\mathrm{n}(\%)$ & $05(16.1)$ & $18(26.1)$ & 0.07 \\
\hline Hypercholesteroemia, $\mathrm{n}(\%)$ & $03(9.6)$ & $40(58)$ & 0.03 \\
\hline Thombolytic therapy, $\mathrm{n}(\%)$ & $11(35.4)$ & $07(10.1)$ & 0.00 \\
\hline Hypotension, $\mathrm{n}(\%)$ & $30(96.7)$ & $08(11.6)$ & 0.07 \\
\hline High degree AV block, $\mathrm{n}(\%)$ & $02(6.4)$ & $02(2.8)$ & 0.00 \\
\hline Cardiogenic shock, $\mathrm{n}(\%)$ & $20(64.5)$ & $02(2.8)$ & 0.00 \\
\hline Death, $\mathrm{n}(\%)$ & $13(41.9)$ & & \\
\hline
\end{tabular}


Table 2: Multivariate analysis of the independent prognostic value of RVI with other clinical criteria for the incidence of death:

\begin{tabular}{|c|c|c|c|}
\hline Clinical & Relative risk of Death & $95 \%$ CI & P value \\
\hline $\begin{array}{c}\text { Age group (yrs) } \\
28-40(\mathrm{R})\end{array}$ & & & $\mathrm{P}=0.21$ \\
\hline $41-50$ & 6.424 & $0.351-117.6$ & $\mathrm{P}=0.23$ \\
\hline $51-60$ & 5.356 & $0.335-85.53$ & $\mathrm{P}=0.32$ \\
\hline$>60$ & 3.959 & $0.257-61.02$ & $\mathrm{P}=0.15$ \\
\hline Sex (male- R) & 0.91 & $0.003-2.509$ & $\mathrm{P}=0.17$ \\
\hline Smoker & 0.18 & $0.015-2.140$ & $\mathrm{P}=0.11$ \\
\hline Hypertension & 0.21 & $0.033-1.454$ & $\mathrm{P}=0.89$ \\
\hline Diabetes & 0.85 & $0.095-7.757$ & $\mathrm{P}=0.62$ \\
\hline Hypercholesteroemia & 0.51 & $0.038-7.077$ & $\mathrm{P}=0.52$ \\
\hline Thombolytic & 0.59 & $0.119-2.962$ & $\mathrm{P}=0.00$ \\
\hline RV infarction & 88.37 & $7.334-1064.803$ & \\
\hline
\end{tabular}

* R= Reference Category; Sex (female- R); Smoker (No-R); Hypertension (No-R);

Diabetes (No-R); Dyslipidaemia (No-R); Thombolytic (Yes-R); RV infarction (No-R).

Table 3: Multivariate analysis of the independent value of RVI with other clinical criteria for the incidence of major complications:

\begin{tabular}{|c|c|c|c|}
\hline Clinical & \multicolumn{3}{|c|}{ Major Complications } \\
\hline $\begin{array}{l}\text { Age group (yrs) } \\
28-40(R)\end{array}$ & Hypotension & High degree AV block & Cardiogenic shock \\
\hline $41-50$ & $\begin{array}{c}2.83(0.146-5493) \\
P=0.49\end{array}$ & $\begin{array}{c}1.2 \mathrm{E}+008(0.00-) \\
P=0.99\end{array}$ & $\begin{array}{c}0.825(0.06-10.38) \\
P=0.88\end{array}$ \\
\hline $51-60$ & $\begin{array}{c}1.84(0.081-42.05) \\
\mathrm{P}=0.70\end{array}$ & $\begin{array}{c}90702785(0.00-) \\
\mathrm{P}=0.99\end{array}$ & $\begin{array}{c}2.533(0.248-25.86) \\
\mathrm{P}=0.43\end{array}$ \\
\hline$>60$ & $\begin{array}{c}10.04(0.397-254.5) \\
P=0.16\end{array}$ & $\begin{array}{c}4.7 \mathrm{E}+008(0.00-) \\
\mathrm{P}=0.99\end{array}$ & $\begin{array}{c}4.074(.348-47.717) \\
\mathrm{P}=0.26\end{array}$ \\
\hline Sex & $\begin{array}{c}1.501(0.119-18.87) \\
\mathrm{P}=0.75\end{array}$ & $\begin{array}{c}0.367(.026-5.100) \\
\mathrm{P}=0.45\end{array}$ & $\begin{array}{c}0.643(0.03-11.223) \\
P=0.76\end{array}$ \\
\hline Smoker & $\begin{array}{c}0.62(0.105-3.787) \\
\mathrm{P}=0.61\end{array}$ & $\begin{array}{c}0.221(0.041-1.193) \\
\mathrm{P}=0.07\end{array}$ & $\begin{array}{c}0.09(0.006-1.51) \\
\mathrm{P}=0.09\end{array}$ \\
\hline Hypertension & $\begin{array}{c}\text { 1.142(.182-7.155) } \\
\mathrm{P}=0.88\end{array}$ & $\begin{array}{c}1.23(0.183-8.306) \\
P=0.82\end{array}$ & $\begin{array}{c}.529(.091-3.067) \\
P=0.47\end{array}$ \\
\hline Diabetes & $\begin{array}{c}0.497(0.062-3.946) \\
\mathrm{P}=0.50\end{array}$ & $\begin{array}{r}0.00(0.00-) \\
\mathrm{P}=0.99 \\
\end{array}$ & $\begin{array}{c}.996(.146-6.808) \\
\mathrm{P}=0.99\end{array}$ \\
\hline Hypercholesteroemia & $\begin{array}{c}0.602(0.067-5.381) \\
\mathrm{P}=0.65\end{array}$ & $\begin{array}{c}0.00(0.00-) \\
\mathrm{P}=0.99\end{array}$ & $\begin{array}{c}2.838(.258-31.254) \\
\mathrm{P}=0.39\end{array}$ \\
\hline Thombolytic & $\begin{array}{c}1.867(0.35-9.966) \\
\mathrm{P}=0.46\end{array}$ & $\begin{array}{c}1.131(0.215-5.954) \\
\mathrm{P}=0.88\end{array}$ & $\begin{array}{c}1.197(.235-6.081) \\
\mathrm{P}=0.82\end{array}$ \\
\hline RV infarction & $\begin{array}{c}394.22(32.04-4849.07) \\
\mathrm{P}=0.00\end{array}$ & $\begin{array}{c}0.409(0.058-2.879) \\
\mathrm{P}=0.36\end{array}$ & $\begin{array}{c}272.36(16.389-4526.35) \\
\mathrm{P}=0.00\end{array}$ \\
\hline
\end{tabular}

* Values shown are relative risks followed in parentheses by 95 percent confidence interval.

* R= Reference Category; Sex (female- R); Smoker (No-R); Hypertension (No-R);

Diabetes (No-R); Dyslipidaemia (No-R); Thombolytic (Yes-R); RV infarction (No-R).

\section{Discussion}

The classic report of Cohn and coworkers ${ }^{2}$ in 1974 for the first time established right ventricular infarction as a separate entity. Sharpe et al, ${ }^{8}$ Garty et $\mathrm{al}^{9}{ }^{9}$ Croft et $\mathrm{al}^{10}$ and Rodigues ${ }^{11}$ EA observed the incidence of right ventricular infarction $40 \%$, 52.7\%, 47.6 and 50\% respectively. Recently, Chockalingram $\mathrm{A}^{12}$ had showed $37 \%$ in India,
Akbar MA et $\mathrm{al}^{13}$ showed $30 \%$ in Pakistan and Hossain $\mathrm{M}^{14}$ documented $40 \%$ incidence RV infarction among inferior $\mathrm{MI}$ patients in Bangladesh. Electrocardiographic criterion used by this study documented 31\% RVI with acute inferior myocardial infarction. This finding is consistent with the previous studies. 
In this study we documented a low incidence (6.4\%) of high grade AV block in group A and a relatively high incidence $(11.6 \%)$ in group B patients. Similar result was also found by Mehta $\mathrm{SR}^{15}$. But this finding is contrary to some of the previous studies reported as many as $48 \% \mathrm{AV}$ block in RVI patients ${ }^{16}$. Chockalingram A. ${ }^{12}$ Hossain $^{14}$ also reported a higher incidence. An explanation could therefore, be that dual or collateral blood supply to the AV node is functionally common.

Cardiogenic shock is relatively infrequent but leading cause of mortality in RVMI patients. ${ }^{17}$ Zehender et $\mathrm{al}^{18}$ found $11 \%$ cardiogenic shock in his observation. We had a higher incidence (64.5\%) of cardiogenic shock in group B patients in comparison to group A patients without RVI and mortality was higher in group $\mathrm{B}$ than group $\mathrm{A}$ (64.5\% vs 2.8\%; p=0.00). Akbar et al $^{13}$ also observed a similar significant difference of cardiogenic shock between two groups of patients $(\mathrm{p}<.004)$.

The most striking finding was that while RVI has been described as a reversible cause of cardiogenic shock, ${ }^{2,19}$ study patients who developed cardiogenic shock due to RVI died as a consequence. Although most patients (96.7\%) received volume expansion and ionotopic supports $(41.9 \%)$, most $(80 \%)$ of them were nonresponding to therapy and thirteen patients (41.9\%) had died from irreversible cardiogenic shock.

This study confirms the prognostic effect of RV infarction in a good number of patients. Patients with RV infarction had a 14 percent risk of death and a 22 percent risk of major complications during hospitalization. In the absence of RV infarction, no patients died during the first 24hrs of hospital stay, on the other hand four patients (13\%) of RV infarction died within this period. As compared with all clinical variables at the time of admission, RV infarction was associated with a relative risk of in-hospital mortality of 88.37 (95\% confidence interval, 27.33 to $1064.80 ; \mathrm{p}=0.000$ ) and a risk of major complications of hypotension 394.2 (95\% confidence interval, 32.04 to 4849.07; $\mathrm{p}=0.000)$ and cardiogenic shock 272.36 (95\% confidence interval, 16.38 to 4526.35 ; $\mathrm{p}=0.000$ ). Ultimately, 97 percent of patients without evidence of RV infarction at the time of admission were discharged from the hospital, as compared with only 58 percent of those in whom RV infarction complicated the acute inferior myocardial infarction.

The independent prognostic value of RV infarction was assessed by a multiple logistic regression analysis in which we included all the other significant prognostic factors available at the time of admission (age, sex, smoking, hypertension, diabetes, thombolytic therapy). After this adjustment RV infarction (Table 2) was observed as one of the most powerful independent predictors of in-hospital death and major complications (Table 3) during hospitalization in patients with acute inferior myocardial infarction.

\section{Conclusion}

Right ventricular infarction is frequent in acute inferior myocardial infarction. It carries a high risk of mortality and major complications during hospitalization. Independent prognostic weight of $\mathrm{RV}$ infarction remains supreme when it compares with all other prognostic determinants.

\section{References}

1. Cintron G: Right ventricular myocardial infarction. Arab journal of Medicine 1983;3:41

2. Cohn JN, Guiha NH, Broder MI, Limas CJ. Right ventricular infarction: Clinical and haemodynamic features. Am J cardiol 1974; 33:209-214.

3. Forman MB , Goodin J, Phelan B, Kopelman H, Virmani R. Electrocardiograpfic changes associated with isolated right ventricular infarction: J Am Coll Cardiol 1984;4;650-643.

4. Dell'Italia KJ, Starling MR, O'rourke Ra. Physical examination for exclusion of haemodynamically important Right ventricular infarction. Ann Intern Med. 1983;99:608-611

5. Cintron GB, Hermandez E, Linares E, Aranda JM: Bedside recognition, incidence and clinical course of Right ventricular myocardial infarction. J Am Coll Cardiol 1981;47:224-227 .

6. Lopez-Sendon J, Coma-Canella I, Alcasena S, Seoane J, Gamallo C. Electrocardiographic findings in acute right ventricular infarction: sensitivity and specificity of electrocardiographic alterations in right 
precordial leads $\mathrm{V}_{4} \mathrm{R}, \mathrm{V}_{3} \mathrm{R}, \mathrm{V}_{1}, \mathrm{~V}_{2}$ and $\mathrm{V}_{3}$. J Am Coll Cardiol 1985;6:1273-1279.

7. Erhardt HO, Todriman $\mathrm{T}$, Ninio R, et al: The single right sided precordial lead in the diagnosis of Right ventricular involvement in inferior myocardial infarction. Am Heart J 1976;91:571

8. Sharpe DN, Botnivick $\mathrm{EH}$ et al: The noninvasive diagnosis of Right ventricular infarction: Circulation 1978;57: 483-490.

9. Garty I, Bavzilany J, Bloch L. The diagnosis and early complications of right ventricular infarction. Eur J Nuclear Med 1984;9:453-60

10. Croft $\mathrm{CH}$, Nicod P, Corbett JR, et al. Detection of acute right ventricular infarction by right precordial electrocardiography. Am J Cardiol 1982; 50:421427.

11. Rodrigues EA, Dewhurst NG, Smart LM, Hannan WJ. Diagnosis and prognosis of right ventricular infarction. Br Heart Journal 1986; 56:19-26

12. Chockalingam A, Gnanavelu G, Subramanium T, Dorairajan S, Chockalingam V. Right ventricular infarction: Presentation and acute outcomes. Angiology. 2005; 56(4); 371-376

13. Akbar MA, Nadeem MA, Waseem T, Mujib F, Khan $\mathrm{AH}$. Right Ventricular Involvement in Inferior Myocardial Wall Infarction: Incidence, Clinical Spectrum and In-Hospital Outcome Ann King Edward Med Coll Apr - Jun 1999; 5(2):152-5.
14. Hossain M. Right ventricular involvement in acute inferior myocardial infarction. Clinical and noninvasive approach to diagnosis. NICVD, Dhaka, 1987

15. Mehta SR, Elikeboom JW, Nataranjan MK, Diaz R, Gibbons RJ, Yusuf S. Impact of Right ventricular involvement on mortality and morbidity in patients with inferior myocardial infarction. Am Coll Cardiol, $2001 ; 37: 37-43$

16. Braat $\mathrm{SH}$, de Zwaan $\mathrm{C}$, Brugada $\mathrm{P}$, Coenegracht $\mathrm{JM}$, Wellens HJJ. Right ventricular involvement with acute inferior wall myocardial infarction identifies high risk of developing atrioventricular nodal conduction disturbances. Am Heart J 1984; 107:1183-1187.

17. Bueno H, Lopez-Palop R,Bermejo J, Lopez-Sendon J. In hospital outcome of elderly patients with acute inferior myocardial infarction and Right ventricular involvement. Circulation.1997; 96:436-441

18. Zehender M, Kasper W, Kauder E, et al. Right ventricular infarction as an independent predictor of prognosis after acute inferior myocardial infarction. N Engl J Med.1993;328;981-988

19. Lioyd EA, Gersh BJ et al: Haemodynamic spectrum of dominant right ventricular infarctionon 19 patients. Am J Cardiol 1948;48:1016

20. Legrand $V$, Rigo $P$, Smeets JP, Collignon $P$, Kulbertus HE. Right ventricular infarction diagnosed by $99 \mathrm{~m}$ technetium pyrophosphate scintigraphy: clinical course and follow-up. Eur Heart J 1983; 4:9-19. 